\title{
Changes in Activities of Circulating MMP-2 and MMP-9 in Patients Suffering From Heart Failure in Relation to Gender, Hypertension and Treatment: a Cross-Sectional Study
}

\author{
E. GIANNAKOS ${ }^{1}$, E. VARDALI ${ }^{2}$, M. BARTEKOVA ${ }^{1,3}$, M. FOGARASSYOVA ${ }^{3}$, \\ M. BARANCIK ${ }^{3}$, J. RADOSINSKA $^{1,3}$
}

${ }^{1}$ Institute of Physiology, Faculty of Medicine, Comenius University in Bratislava, Slovak Republic, ${ }^{2}$ Center of Health, Koufalia, Thessaloniki, Greece, ${ }^{3}$ Institute for Heart Research, Slovak Academy of Sciences, Bratislava, Slovak Republic

Received June 25, 2016

Accepted July 8, 2016

\section{Summary}

Matrix metalloproteinases (MMPs) play an important role in the pathogenesis of heart failure (HF). Our aim was to determine the activities of circulating MMP-2 and MMP-9 in patients with HF in respect of gender, comorbidities and treatment $(n=51)$. We did not reveal any differences in circulating pro-MMP-2 and pro-MMP-9 activities between the patients with $\mathrm{HF}$ and without it. However, there was a decrease in activity of pro-MMP-2 in treated hypertensive participants versus healthy ones. In contrast, we observed increased pro-MMP-2 activity in hypertensive participants with coexistent HF versus hypertensive participants without HF. In addition, a decrease in pro-MMP-2 activity was shown in women suffering from HF versus men suffering from HF. In conclusion, potential inhibitory effect of antihypertensive treatment on pro-MMP-2 activity was found. Coexistent HF with hypertension probably reduces the inhibitory effect of antihypertensive treatment on pro-MMP-2 activity. Our data also suggest the role of potential cardioprotective factors influencing the activity of pro-MMP-2 in women.
\end{abstract}

\section{Key words}

Circulating matrix metalloproteinases (MMPs) - Human heart failure $\bullet$ Hypertension $\bullet$ Treatment $\bullet$ Gender

\section{Corresponding author}

J. Radosinska, Institute of Physiology, Faculty of Medicine, Comenius University in Bratislava, Slovak Republic. E-mail: jana.radosinska@fmed.uniba.sk
Altered turnover of extracellular matrix (ECM) in the heart contributes to the development of heart failure (HF) (Spinale 2002). Matrix metalloproteinases (MMPs) are endopeptidases that play a crucial role in the dynamic processing of the ECM (Muller and Dhalla 2012, Vasku et al. 2014). MMP-2 and MMP-9 are two significant enzymes that take place in heart remodeling (Bartekova et al. 2015, Barancik et al. 2013) and the development of chronic HF (Meluzin et al. 2013, Liu et al. 2006). Since activities of MMP-2 and MMP-9 may serve as potential biomarkers of prognosis of $\mathrm{HF}$ (Sanchis et al. 2015), we aimed to determine the activity of circulating MMP-2 and MMP-9 in patients with chronic HF in respect of gender, comorbidities and treatment.

Randomly selected individuals $(\mathrm{n}=51)$ from the Centre of Health (Koufalia, Greece) were included in this study. The study was approved by the local Ethical Committee at the Centre of Health in Koufalia, Greece. The patients suffering from $\mathrm{HF}$ were classified according New York Heart Association (NYHA): class I - $9 \%$, class II - $44 \%$, class III - $34 \%$, class IV $-13 \%$. All hypertensive patients included in our study suffer from primary hypertension. Characteristics of participants are summarized in Table 1. Venous blood samples were collected after overnight fasting and immediately centrifuged at $2000 \mathrm{~g}$ for $10 \mathrm{~min}$ at $4{ }^{\circ} \mathrm{C}$. Plasma samples were stored at $-80^{\circ} \mathrm{C}$ until analyses. The gelatinolytic activities of MMPs were analyzed by

PHYSIOLOGICAL RESEARCH • ISSN 0862-8408 (print) • ISSN 1802-9973 (online)

(c) 2016 Institute of Physiology of the Czech Academy of Sciences, Prague, Czech Republic

Fax+420 241062 164, e-mail: physres@biomed.cas.cz, www.biomed.cas.cz/physiolres 
zymography in polyacrylamide gels containing gelatin as a substrate as described previously (Bartekova et al. 2015). Activities of the MMPs were detected according the densities of transparent bands against a dark-blue background using Carestream software for quantification. The data are presented as means $\pm \mathrm{SD}$. Normality was analyzed by Shapiro-Wilk's test. Student's t-test or one-way ANOVA followed by Tukey HSD test were used where appropriate. Differences were considered as significant at $\mathrm{p}<0.05$.

Table 1. Characteristics of participants.

\section{Characteristic}

\begin{tabular}{lc}
\hline Men/women & $17 / 34$ \\
Age (men/women) & $64.6 \pm 13.5$ \\
Healthy participants & $(67.8 \pm 11.6 / 62.9 \pm 14.3)$ \\
Without HF/with HF & 10 \\
Men with HF/women with & $19 / 32$ \\
HF & $12 / 20$ \\
Normotensives/hypertensives & $28 / 23$ \\
Hypertensives with HF/ & $15 / 8$ \\
hypertensives without HF & \\
\hline
\end{tabular}

All our zymograms revealed mainly gelatinolytic activities of $72 \mathrm{kDa}$ MMP-2 (pro-MMP-2) and $92 \mathrm{kDa}$ MMP-9 (pro-MMP-9) (Fig. 1A). Firstly, when the patients were divided into a subgroup of people with chronic HF and without HF, no significant differences in activities of pro-MMP-2 and pro-MMP-9 were found (Fig. 1B). Secondly, we determined activity of pro-MMP-2 and pro-MMP-9 according to gender of participants. There were no gender differences between participants without HF. In contrast, we detected lower activity of pro-MMP-2 in women with HF compared to men with HF (Fig. 1C). Additionally, no differences were found in pro-MMP-9 activities between these groups (not shown). Thirdly, we were focused on pro-MMP-2 and pro-MMP-9 activities in relation to statin therapy. We have found no significant differences in the activity of pro-MMP-2 and pro-MMP-9 between HF patients without statin therapy and patients suffering from HF following statin regimen (not shown). Finally, comparing following three groups: healthy participants, hypertensive patients and hypertensive patients suffering from HF, we detected a lower activities of pro-MMP-2 in hypertensive patients in comparison with healthy ones as well as with hypertensive patients suffering from HF (Fig. 1D). No differences in activities of pro-MMP-9 were observed (not shown).

Taken together, our study demonstrated a reduction in gelatinolytic activities of pro-MMP-2 $(p=0.0024)$ in hypertensive participants versus healthy ones. We observed lower pro-MMP-2 activity in hypertensive participants compared with hypertensive participants with coexistent HF $(p=0.018)$. We found a decrease in pro-MMP-2 activity in women in contrast to men, both suffering from HF $(p=0.023)$. We failed to detect differences in pro-MMP-2 and pro-MMP-9 activities in patients with HF compared with healthy participants. Correlation coefficients between severity of HF according NYHA and activity of both determined pro-MMPs have not reached the significant level $(\mathrm{r}=0.23$, $\mathrm{p}=0.2$ for MMP-2; $\mathrm{r}=0.005, \mathrm{p}=0.98$ for MMP-9). Since we did not detected changes in pro-MMP-9 activities among the groups at all, pro-MMP-2 seems to be more sensitive parameter reflecting gender and hypertension.

Hypertension is a strong factor facilitating the progression of HF, but discrepancies have been observed in terms of MMPs activity (Fontana et al. 2012). Our data are in concordance with study showing decreased MMP-2 plasma level associated with left ventricular hypertrophy in hypertensives (Ahmed et al. 2006). Additionally, all hypertensives included in our study were treated at least 3 years with some kind of antihypertensive therapy; therefore the effect of the antihypertensive therapy should be taken into the consideration. Previously, it has been shown that either activities or levels of MMP-2 could be decreased by ACE inhibitors ( $\mathrm{Li}$ et al. 2000), hydrochlorothiazide (Ceron et al. 2010) and sartans (Derosa et al. 2011). HF is an independent risk factor increasing the activity of MMPs (Spinale et al. 2000, Liu et al. 2006). In the present study, we observed decreased pro-MMP-2 activities in hypertensives compared with the hypertensives with coexistent HF. Thus it might be suggested that when HF is coexistent with hypertension the inhibitory effect of antihypertensive therapy may not be sufficient to keep the activity of MMPs in lower levels.

Voloshenyuk and Gardner (2010) demonstrated the positive influence of estrogen replacement on cardiac ECM protein profiles in the acute and chronic stages of volume overload in ovariectomized rats. Our data showing lower pro-MMP-2 activity in woman suffering from HF in comparison to men are in concordance with 


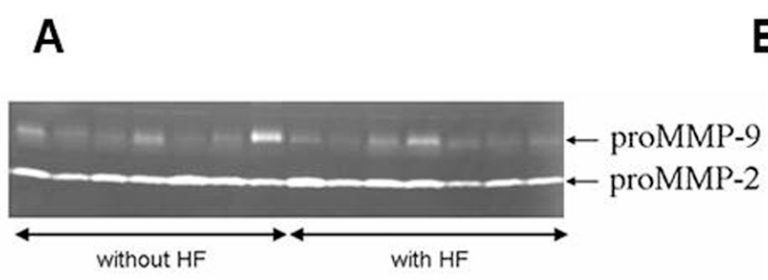

\section{C}

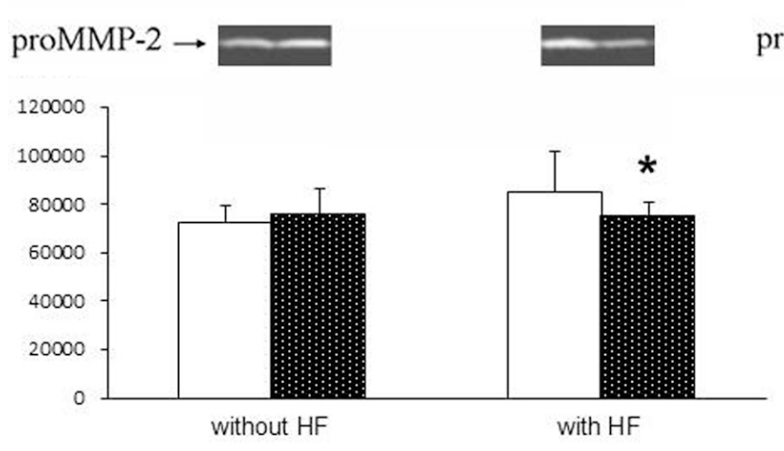

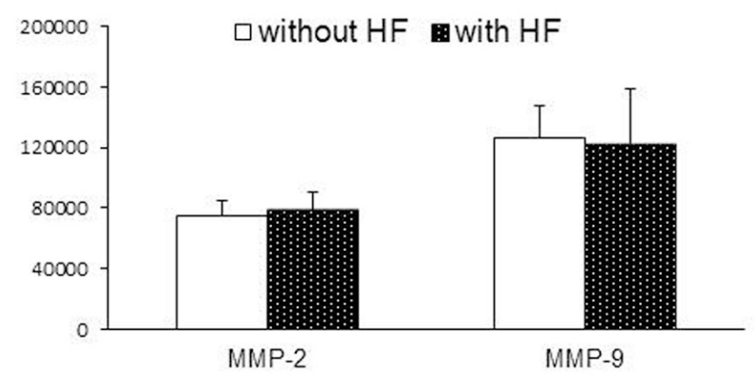

B

D proMMP-2 -
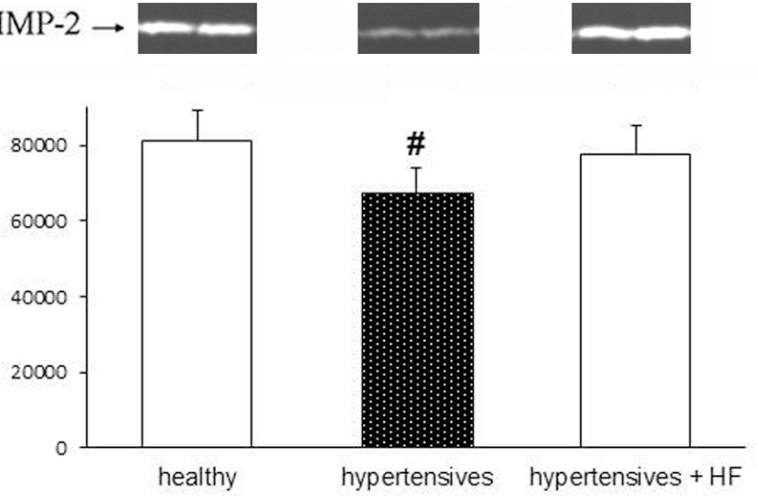

Fig. 1. A. Representative zymogram of MMP-2 and MMP-9 activities. B. Quantitative analysis of pro-MMP-2 and pro-MMP-9 activities in participants without and with HF. C. Representative zymograms and gender differences in pro-MMP-2 activities in participants without and with $\mathrm{HF}, * \mathrm{p}<0.05$ women with HF versus men with HF. D. Representative zymograms and quantitative analysis of pro-MMP-2 activities in healthy participants, hypertensive participants and hypertensive participants with coexistent $\mathrm{HF}$, $\mathrm{p}<<0.05$ healthy versus hypertensives and $\mathrm{p}<0.05$ hypertensives versus hypertensives and coexistent HF.

this finding suggesting a favor of female gender in prevention of MMP activation.

Focusing on possible changes in activities of MMPs in respect of statin treatment, we have found no significant differences in patients with or without statin therapy in our study. The similar results were observed in patients with abdominal aortic aneurism (Muehling et al. 2008) and in patients with coronary artery disease (Bencsik et al. 2015). However, some studies indicated opposite trend - inhibitory effect of statins on MMPs activities (Hopps and Caimi 2015, Sapienza et al. 2014).

The relatively small group (51 participants) can limit our interpretation validity. Although our results demonstrate an association between pro-MMP-2 activities and hypertension or gender, they do not prove a direct causality between these variables. Circulating MMPs may originate from different tissues and thus may not reflect changes occurring in the heart.

In conclusion, despite the study limitations, we have shown several interesting and novel findings on MMPs activities in patients suffering from HF in respect of gender, statin treatment and coexisting hypertension.

\section{Conflict of Interest}

There is no conflict of interest.

\section{Acknowledgements}

Supported by grants: VEGA SR 1/0032/14, 2/0108/15 and APVV 0348-12.

\section{References}

AHMED SH, CLARK LL, PENNINGTON WR, WEBB CS, BONNEMA DD, LEONARDI AH, MCCLURE CD, SPINALE FG, ZILE MR: Matrix metalloproteinases/tissue inhibitors of metalloproteinases: relationship between changes in proteolytic determinants of matrix composition and structural, functional, and clinical manifestations of hypertensive heart disease. Circulation 113: 2089-2096, 2006. 
BARANCIK M, OKRUHLICOVA L, FOGARASSYOVA M, BARTEKOVA M, SLEZAK J: Mediastinal irradiation modulates myocardial and circulating matrix metalloproteinases. Exp Clin Cardiol 18S: 37A-40A, 2013.

BARTEKOVA M, SIMONCIKOVA P, FOGARASSYOVA M, IVANOVA M, OKRUHLICOVA L, TRIBULOVA N, DOVINOVA I, BARANCIK M: Quercetin improves postischemic recovery of heart function in doxorubicintreated rats and prevents doxorubicin-induced matrix metalloproteinase-2 activation and apoptosis induction. Int J Mol Sci 16: 8168-8185, 2015.

BENCSIK P, SASI V, KISS K, KUPAI K, KOLOSSVÁRY M, MAUROVICH-HORVAT P, CSONT T, UNGI I, MERKELY B, FERDINANDY P: Serum lipids and cardiac function correlate with nitrotyrosine and MMP activity in coronary artery disease patients. Eur J Clin Invest 45: 692-701, 2015.

CERON CS, CASTRO MM, RIZZI E, MONTENEGRO MF, FONTANA V, SALGADO MC, GERLACH RF, TANUS-SANTOS JE: Spironolactone and hydrochlorothiazide exert antioxidant effects and reduce vascular matrix metalloproteinase-2 activity and expression in a model of renovascular hypertension. Br J Pharmacol 160: 77-87, 2010.

DEROSA G, MAFFIOLI P, FERRARI I, PALUMBO I, RANDAZZO S, FOGARI E, D'ANGELO A, CICERO AF: Different actions of losartan and ramipril on adipose tissue activity and vascular remodeling biomarkers in hypertensive patients. Hypertens Res 34: 145-151, 2011.

FONTANA V, SILVA PS, GERLACH RF, TANUS-SANTOS JE: Circulating matrix metalloproteinases and their inhibitors in hypertension. Clin Chim Acta 413: 656-662, 2012.

HOPPS E, CAIMI G: Matrix metalloproteases as a pharmacological target in cardiovascular diseases. Eur Rev Med Pharmacol Sci 19: 2583-2589, 2015.

LI H, SIMON H, BOCAN TM, PETERSON JT: MMP/TIMP expression in spontaneously hypertensive heart failure rats: the effect of ACE- and MMP-inhibition. Cardiovasc Res 46: 298-306, 2000.

LIU P, SUN M, SADER S: Matrix metalloproteinases in cardiovascular disease. Can J Cardiol 22: 25B-30B, 2006.

MELUZIN J, TOMANDL J, PODROUZKOVA H, GREGOROVA Z, SOSKA V, DOBSAK P, PECEN L, STEPANOVA R: Can markers of collagen turnover or other biomarkers contribute to the diagnostics of heart failure with normal left ventricular ejection fraction? Biomed Pap Med Fac Univ Palacky Olomouc Czech Repub 157: 331-339, 2013.

MUEHLING B, OBERHUBER A, SCHELZIG H, BISCHOFF G, MARX N, SUNDER-PLASSMANN L, OREND $\mathrm{KH}$ : Effect of statin therapy on serum activity of proteinases and cytokines in patients with abdominal aortic aneurysm. Vasc Health Risk Manag 4: 1433-1437, 2008.

MULLER AL, DHALLA NS: Role of various proteases in cardiac remodeling and progression of heart failure. Heart Fail Rev 17: 395-409, 2012.

SANCHIS L, ANDREA R, FALCES C, LLOPIS J, MORALES-RUIZ M, LÓPEZ-SOBRINO T, PÉREZ-VILLA F, SITGES M, SABATE M, BRUGADA J: Prognosis of new-onset heart failure outpatients and collagen biomarkers. Eur J Clin Invest 45: 842-849, 2015.

SAPIENZA P, BORRELLI V, STERPETTI AV, BIACCHI D, VENTURINI L, TARTAGLIA E, BONONI M, DI MARZO L: Statins reduce levels of metalloproteinases in patients with carotid occlusive disease. Int Angiol 33: 530-539, 2014.

SPINALE FG: Matrix metalloproteinases: regulation and dysregulation in the failing heart. Circ Res 90: 520-530, 2002.

SPINALE FG, COKER ML, HEUNG LJ, BOND BR, GUNASINGHE HR, ETOH T, GOLDBERG AT, ZELLNER JL, CRUMBLEY AJ: A matrix metalloproteinase induction/activation system exists in the human left ventricular myocardium and is upregulated in heart failure. Circulation 102: 1944-1949, 2000.

VASKU A, BIENERTOVA-VASKU J, PARENICA J, PAVKOVA GOLDBERGOVA M, NOVAK J, CHMELIKOVA M, HONSOVA D, LIPKOVA J, KALA P, SPINAR J: Central pulse pressure and variability in matrix metalloproteinases genes and their inhibitors in patients with ischemic heart disease. Physiol Res 63 (Suppl 4): S497-S507, 2014.

VOLOSHENYUK TG, GARDNER JD: Estrogen improves TIMP-MMP balance and collagen distribution in volumeoverloaded hearts of ovariectomized females. Am J Physiol Regul Integr Comp Physiol 299: R683-R693, 2010. 